\title{
Apontamentos sobre a História da Psicologia Social no Brasil
}

\author{
Notes on the history of Social Psychology in Brazil \\ Apuntes sobre la historia de la Psicología Social en Brasil
}

\author{
Mariana Prioli Cordeiro* \\ Universidade de São Paulo - IPUSP, São Paulo, São Paulo, Brasil
}

\author{
Mary Jane Paris Spink** \\ Pontifícia Universidade Católica de São Paulo - PUC-SP, São Paulo, São Paulo, \\ Brasil
}

\begin{abstract}
RESUMO
Neste artigo, buscamos apresentar algumas das abordagens teóricas, grupos de pesquisa e instituições que fizeram e fazem parte do vasto (e diverso) campo da psicologia social brasileira. Para isso, em um primeiro momento, retomamos o modo como a história dessa ciência costuma ser contada colocando a "crise de referência" da década de 1970 como um importante momento de inflexão, no qual ganham força a oposição ao modelo positivista de ciência e a necessidade de desenvolver abordagens críticas e comprometidas com a transformação social. Em um segundo momento, apresentamos algumas das abordagens teórico-metodológicas desenvolvidas após esse momento de "crise". Mais especificamente, abordamos o desenvolvimento da análise institucional, da psicologia sócio-histórica, da teoria das representações sociais e das abordagens construcionistas.

Palavras-chave: história da psicologia social, análise institucional, teoria das representações sociais, psicologia sócio-histórica, abordagens construcionistas.
\end{abstract}

\begin{abstract}
In this article, we aim to present some of the theoretical approaches, research groups and institutions that that have been part of the vast (and diverse) field of Brazilian social psychology. With this in mind, we begin with the history of the subject as it is usually told, placing the "crisis of reference" of the 1970's as an important turning point and two important ideas which gain ground then: opposing forces to the positivistic model of science and the recognition of the need to develop critical approaches committed to social transformation. After that, we present some of the theoreticalmethodological approaches developed after this moment of "crisis". More specifically, we will tackle the development of institutional analysis, socialhistorical psychology, social representation theory and constructionist perspectives.
\end{abstract}


Keywords: history of social psychology, institutional analysis, social representation theory, socio-historical psychology, constructionist perspectives.

\section{RESUMEN}

En este artículo, buscamos presentar algunos de los abordajes teóricos, grupos de investigación e instituciones que formaron y forman parte del vasto (y diverso) campo de la psicología social brasileña. Para ello, en un primer momento, retomamos el modo en que la historia de esta ciencia suele ser relatada - colocando la "crisis de referencia" de la década de 1970 como un importante momento de inflexión, en el que ganan fuerza la oposición al modelo positivista de ciencia y la necesidad de desarrollar enfoques críticos y comprometidos con la transformación social. En un segundo momento, presentamos algunos de los enfoques teóricometodológicos desarrollados después de ese momento de "crisis". Más específicamente, abordamos el desarrollo del análisis institucional, de la psicología socio-histórica, de la teoría de las representaciones sociales y de los abordajes construccionistas.

Palabras clave: história de la psicología social, análisis institucional, teoria de las representaciones sociales, abordajes construccionistas.

Qualquer história é uma construção mais ou menos engenhosa de algo que pode ser feito de modo inteiramente diferente.

(John Law)

No Brasil, a Psicologia Social é uma arena de diversidades: ela possui várias definições, abordagens teóricas e objetos de estudo. Algumas(uns) autoras(es) a consideram uma subárea da Psicologia, outras(os) acreditam que ela é a interseção da Psicologia com a Sociologia. Há ainda aquelas(es) que afirmam que o adjetivo "social" não delimita uma subdivisão temática ou conceitual, mas enfatiza a importância do compromisso político que toda(o) psicóloga(o) deve ter. Umas(ns) baseiam-se nas leituras do Materialismo Histórico e Dialético para estruturar suas pesquisas ou sua prática profissional. Outras(os) preferem as leituras construcionistas ou ainda a Teoria das Representações Sociais. Há psicólogos(as) sociais cognitivistas, behavioristas, psicanalistas, comunitários... (Cordeiro, 2017; Cordeiro \& Spink, 2014).

Diante de tamanha diversidade, seria impossível escrevermos um artigo que apresentasse a história da Psicologia Social brasileira. Desse modo, falaremos apenas de algumas psicologias sociais que são feitas em nosso país. Assim como qualquer recorte, o que fazemos aqui é fruto de escolhas. Escolhas guiadas por nossas trajetórias de pesquisa, por nossas experiências como docentes da área, por nossos posicionamentos. Escolhas que produzem uma narrativa singular do que foi e do que é a Psicologia Social em nosso país. Mais exatamente, produzem uma narrativa dividida em duas 
partes: a primeira retoma o modo como costumamos contar a história dessa ciência; e a segunda apresenta algumas das abordagens teórico-metodológicas que fazem parte de sua história.

\section{Uma (breve) história da Psicologia Social no Brasil}

Diversas(os) autoras(es) (Bernardes, 2001; Bock \& Furtado, 2007; Cordeiro, 2013; Ferreira, 2011; Mancebo, Jacó-Vilela \& Rocha, 2003; Tittoni \& Jacques, 2001) dividem a história da Psicologia Social brasileira em dois grandes momentos: um anterior e o outro posterior à chamada crise de referência, que assolou essa área do conhecimento na década de 1970. Sustentam que, antes de tal crise, a Psicologia Social brasileira era marcada pela hegemonia do modelo norte-americano, tinha uma base positivista e defendia a neutralidade da ciência, passando, após a crise, a fazer uma severa crítica ao modelo biologicista e, principalmente, a defender uma ciência comprometida com a transformação social.

Mas é importante pontuarmos que essa crise de referência não aconteceu somente no Brasil e nem foi um fenômeno restrito à Psicologia Social. Pelo contrário, este movimento de questionamento - ou, como diria Lallement (2008), de "pulverização metodológica" e "abalo teórico" - afetou também outras áreas do conhecimento, tal como a Sociologia. De acordo com o autor, as décadas de 1960 e 1970 foram marcadas por uma Sociologia que traduzia, antes de mais nada, o declínio do impulso modernizante do pós-guerra. 0 enfraquecimento da fé na igualdade de oportunidades, bem como o esgotamento das garantias de coesão social pelo simples crescimento econômico, fizeram com que instituições - como a escola, a prisão e a fábrica - fossem questionadas. No caso específico da América Latina, o abalo teórico foi impulsionado, sobretudo, pela situação política vivenciada por alguns países da região. Diante da repressão político-cultural dos regimes autoritários e de uma profunda crise paradigmática, começaram a ganhar espaço abordagens sociológicas "alternativas", como a Sociologia Nacional, a Teoria da Dependência e a Teoria do Novo Autoritarismo (Liedke Filho, 2003).

Nesse mesmo período, a Psicologia Social norte-americana começou a ser problematizada pelos europeus. Na França, por exemplo, a tradição psicanalítica foi retomada após o movimento de maio de 1968 e a tradição norte-americana foi criticada por ser "uma ciência ideológica, reprodutora dos interesses da classe dominante, e produto de condições históricas específicas" (Lane, 1984/2007, p. 11). Esse movimento repercutiu na Inglaterra: em 1972, Israel e Tajfel analisaram a "crise" sob o ponto de vista epistemológico - era "a crítica ao positivismo, que em nome da objetividade [perdia] o ser humano." (Lane, 1984/2007, p. 11). Dois anos mais tarde, é 
publicado o livro Reconstructing Social Psychology (Armistead et al., 1974), com contribuições de muitos psicólogos críticos ao status quo da disciplina.

Foi também nesse período que, no Brasil, começaram a ganhar força as críticas ao conceito de doença mental e ao modelo hegemônico de intervenção psiquiátrica. O foco é deslocado da patologia para a saúde e se enfatiza a importância de ações preventivas junto a populações pobres e desatendidas pelo Estado. Ganhou força, também, a preocupação com a educação popular. Fundamentada nas ideias de Paulo Freire, a alfabetização de adultos passa a ser vista como uma ferramenta de conscientização e resistência contra a opressão do regime militar (Lane, 1996).

Foram, portanto, vários movimentos, várias críticas e vários acontecimentos que criaram o solo epistêmico, social e político para que a chamada "crise de referência" acontecesse, trazendo à tona a necessidade de refletir sobre o papel da Psicologia em um contexto marcado pela violência de Estado, pela miséria e pela desigualdade social.

Quem somos? O que buscamos? Qual nossa contribuição social? Críticas duras eram feitas aos profissionais que serviam ao sistema nas fábricas e consultórios particulares. A quem estamos servindo? era a pergunta chave. Começava a cair por terra a visão de uma ciência neutra e uma prática descomprometida. (Bock \& Furtado, 2010, p. 510).

De acordo com Bernardes (2001), esse movimento de questionamento da Psicologia Social hegemônica começou a se fortalecer no Brasil e em outros países da América Latina durante os Congressos da Sociedade Interamericana de Psicologia (SIP) realizados em Miami, EUA (1976) e em Lima, Peru (1979). Os principais motivos de insatisfação eram: a dependência teóricometodológica, principalmente dos Estados Unidos, a descontextualização dos temas abordados, a superficialidade e a simplificação das análises desses temas, a individualização do social e ausência de preocupação política. Em suma, "a palavra de ordem era a transformação social." (p. 31) ${ }^{1}$.

No caso específico do Brasil, essas insatisfações levaram ao desenvolvimento e/ou à adoção de diferentes teorias e metodologias: um grupo de pesquisadores, liderado por Georges Lapassade, Osvaldo Saidon e Gregorio Baremblitt, desenvolveu a Análise Institucional; já Silvia Lane coordenou o grupo que estabeleceu os fundamentos do que mais tarde viria a ser conhecido como a Escola Sócio-Histórica; outro grupo, liderado por Ângela Arruda e Celso Sá, começou a realizar trabalhos a partir de teorias europeias, especialmente a das Representações Sociais (Jacó-Vilela, 2007). Poderíamos acrescentar a essa lista várias outras abordagens, tais 
como: as (pós)construcionistas, a Psicanálise Social, a Psicologia da Libertação e a Escola de Frankfurt.

Essas correntes costumam ser agrupadas sob o rótulo de "Psicologia Social Crítica". Mas não podemos deixar de considerar que esse é um termo polissêmico, que abriga teorias com posicionamentos epistemológicos, ontológicos e políticos distintos. Nas palavras de Spink e Spink (2007), a Psicologia Social Crítica é muito mais "uma frente de luta ampla do que um movimento articulado; uma aliança de argumentos e práticas em vez de uma escola." (p. 576). A despeito de suas divergências, no geral, essas abordagens expressam seu caráter crítico de quatro maneiras: 1 ) se contrapondo às bases epistemológicas do conhecimento, "recolocando a ciência como prática social sujeita às vicissitudes dos fazeres humanos" (p. 577); 2) considerando a centralidade da linguagem na produção dos conhecimentos (tanto dos científicos quanto dos do senso comum); 3) radicalizando o potencial transformador da ciência e 4) rompendo com o paradigma positivista de ciência.

Com o fortalecimento das abordagens críticas, começou a se pensar na necessidade de criar uma associação brasileira que representasse as "novas" Psicologias Sociais. No congresso da SIP, em Lima, essa demanda foi amplamente discutida. Falava-se na importância de "fortalecer a organização dos psicólogos ligados à área da Psicologia Social, criando espaços para o diálogo e o avanço desse campo. Além disso, caminhava-se para o fortalecimento de um pensamento latinoamericano na Psicologia, a partir da Psicologia Social." (Lane \& Bock, 2003 , p. 146). Após o congresso, foi nomeada uma comissão para redigir o estatuto da nova associação. No ano seguinte, durante a reunião anual da Sociedade Brasileira para o Progresso da Ciência (SBPC), esse estatuto foi votado e aprovado, instituindo oficialmente a Associação Brasileira de Psicologia Social (ABRAPSO). Segundo as autoras, as intenções políticas da ABRAPSO sempre foram

a construção de uma psicologia social crítica, voltada para os problemas nacionais, acatando diferentes correntes epistemológicas, desde que filiadas ao compromisso social de contribuir para a construção de uma sociedade mais justa. A ABRAPSO nasceu da insatisfação com a psicologia europeia e americana. Os problemas de nossa sociedade, marcada pela desigualdade social e pela miséria, não encontravam soluções na psicologia social importada como um saber universal dos países do Primeiro Mundo. (p. 149).

Hoje, a ABRAPSO é responsável, entre outras coisas, por organizar encontros locais, regionais e nacionais, bem como por editar livros e publicar a revista Psicologia \& Sociedade. 
Além dessa associação, foram criados programas de pós-graduação específicos da área. De acordo com Bomfim (2003), os primeiros cursos de mestrado em Psicologia Social foram criados na década de 1970, na Pontifícia Universidade Católica de São Paulo (PUC-SP) e na Universidade de São Paulo (USP), "engrossando o material disponível para consultas bibliográficas" (p. 138). Hoje, há 7 programas em funcionamento que indicam que sua área básica é Psicologia Social, além de outros 2 programas que possuem "Psicologia Social" em seu nome (Coordenação de Aperfeiçoamento de Pessoal de Nível Superior [Capes], 2016a) (quadro 1). Além disso, há 45 programas com formação geral em Psicologia que possuem linhas de pesquisa voltadas à Psicologia Social (CAPES, 2016b). 
Quadro 1: Programas de pós-graduação com nome e/ou área básica em Psicologia Social ${ }^{2}$

\begin{tabular}{|c|c|c|c|c|}
\hline Nome & $\begin{array}{l}\text { Área } \\
\text { básica }\end{array}$ & Instituição & Nivel & Linhas de pesquisa \\
\hline Psicologia & $\begin{array}{l}\text { Psicologia } \\
\text { Social }\end{array}$ & $\begin{array}{l}\text { Universidade Salgado de } \\
\text { Oliveira (UNIVERSO) }\end{array}$ & $\mathrm{M} / \mathrm{D}$ & $\begin{array}{l}\text { 1) Desenvolvimento sócio-cognitivo, Relações } \\
\text { interpessoais e Educaçào } \\
\text { 2) Cogniçăo social, Organizaçōes e Trabalho }\end{array}$ \\
\hline Psicologia & $\begin{array}{l}\text { Psicologia } \\
\text { Social }\end{array}$ & $\begin{array}{l}\text { Pontificia Universidade } \\
\text { Católica do Rio Grande do } \\
\text { Sul (PUC-RS) }\end{array}$ & $\mathrm{M} / \mathrm{D}$ & $\begin{array}{l}\text { 1) Processos Psicossociais: Identidades, } \\
\text { práticas e contextos } \\
\text { 2) Psicologia Social da Saúde: sujeito, grupos, } \\
\text { instituiçðes. }\end{array}$ \\
\hline Psicologia & $\begin{array}{l}\text { Psicologia } \\
\text { Social }\end{array}$ & $\begin{array}{l}\text { Fundaçào Universidade } \\
\text { Federal de Sergipe (FUFSE) }\end{array}$ & M & $\begin{array}{l}\text { 1) Processo de Subjetivaçào e Politica } \\
\text { 2) Processos sociais e relações intergrupais } \\
\text { 3) Psicanálise e cultura contemporånea } \\
\text { 4) Saúde e desenvolvimento humano }\end{array}$ \\
\hline $\begin{array}{l}\text { Psicologia } \\
\text { (Psicologia } \\
\text { Social) }\end{array}$ & $\begin{array}{l}\text { Psicologia } \\
\text { Social }\end{array}$ & $\begin{array}{l}\text { Pontificia Universidade } \\
\text { Católica de São Paulo } \\
\text { (PUC-SP) }\end{array}$ & $\mathrm{M} / \mathrm{D}$ & $\begin{array}{l}\text { 1) Estudo crítico-cpistemológico das categorias } \\
\text { analíticas da Psicologia Social } \\
\text { 2) Aportes da Psicologja Social à compreensào } \\
\text { de problemas sociais }\end{array}$ \\
\hline Psicologia Social & $\begin{array}{l}\text { Psicologia } \\
\text { Social }\end{array}$ & $\begin{array}{l}\text { Universidade de São Paulo } \\
\text { (USP) }\end{array}$ & $\mathrm{M} / \mathrm{D}$ & $\begin{array}{l}\text { 1) Processos e práticas psicossociais: cultura e } \\
\text { subjetividade } \\
\text { 2) Processos e práticas psicossociais: direitos } \\
\text { humanos, desigualdades e politica }\end{array}$ \\
\hline Psicologia Social & $\begin{array}{l}\text { Psicologia } \\
\text { Social }\end{array}$ & $\begin{array}{l}\text { Universidade Federal da } \\
\text { Paraiba - Jodo Pessoa } \\
\text { (UFPB-JP) }\end{array}$ & $\mathrm{M} / \mathrm{D}$ & $\begin{array}{l}\text { 1) Processos psicossociais } \\
\text { 2) Grupos, relaçøes de poder e sociedade }\end{array}$ \\
\hline $\begin{array}{l}\text { Psicologia Social } \\
\text { e Institucional }\end{array}$ & $\begin{array}{l}\text { Psicologia } \\
\text { Social }\end{array}$ & $\begin{array}{l}\text { Universidade Federal do Rio } \\
\text { Grande do Sul (UFRGS) }\end{array}$ & $\mathrm{M} / \mathrm{D}$ & $\begin{array}{l}\text { 1) Clínica, Subjetividade e Politica } \\
\text { 2) Politicas Públicas e Produçào de } \\
\text { Subjetividade } \\
\text { 3) Redes Sócio-Técnicas, Cognição e } \\
\text { Comunicaçăo }\end{array}$ \\
\hline Psicologia Social & Psicologia & $\begin{array}{l}\text { Universidade do Estado do } \\
\text { Rio de Janeiro (UERJ) }\end{array}$ & $\mathrm{M} / \mathrm{D}$ & $\begin{array}{l}\text { 1) Processos Sociocognitivos e Psicossociais } \\
\text { 2) Contemporaneidade e Processos de } \\
\text { Subjetivaçào } \\
\text { 3) História, Imaginário Social, Cultura }\end{array}$ \\
\hline $\begin{array}{l}\text { Psicologia } \\
\text { Social, do } \\
\text { Trabalho e das } \\
\text { organizaçes } \\
\text { (PSTO) }\end{array}$ & Psicologia & $\begin{array}{l}\text { Universidade de Brasilia } \\
\text { (UNB) }\end{array}$ & $\mathrm{M} / \mathrm{D}$ & $\begin{array}{l}\text { 1) Avaliaçlo e medidas em Psicologia } \\
\text { 2) Comportamento, trabalho e organizaçè } \\
\text { 3) Comportamento no contexto social e } \\
\text { ambiental }\end{array}$ \\
\hline
\end{tabular}

No próximo tópico, apresentaremos algumas das abordagens teóricometodológicas que são discutidas nesses programas de pósgraduação e que fazem parte do grupo heterogêneo de teorias que convencionamos chamar de "Psicologia Social Crítica". 


\section{A diversidade da Psicologia Social brasileira}

\subsection{A análise institucional}

A história da Análise Institucional (AI) no Brasil não pode ser contada sem considerar o contexto político dos países latino-americanos principalmente, da Argentina. De acordo com Cunha, Dorna e Rodrigues (2006), essa abordagem começou a ser desenvolvida na França na década de 1960. Logo em seguida, psicanalistas argentinas(os) entraram em contato com as obras de seus principais expoentes - como René Lourau, Georges Lapassade, Giles Deleuze e Félix Guatarri -, passando a utilizar as ferramentas teóricas e metodológicas por eles propostas para promover transformações, de cunho libertário, nos campos da saúde mental, educação e formação. Mas com o golpe militar de 1976, muitas(os) dessas(es) psicanalistas foram forçados ao exílio e algumas(ns) se mudaram para o Brasil tais como Gregório Baremblitt e Osvaldo Saidón -, o que acabaria imprimido "marcas argentinas e psicanalíticas" na AI brasileira.

No entanto, apesar dessa influência, o desenvolvimento dessa abordagem foi influenciado, permeado e performado também por outros atores e eventos - motivo pelo qual as autoras preferem não falar em história da AI, mas em história do grupalismoinstitucionalismo, um "termo composto mais apto a sintetizar a mescla de perspectivas francesas, argentinas e 'nativas' característica de nosso processo histórico de emergência e expansão da AI." (Cunha, Dorna \& Rodrigues, 2006, p. 3).

A entrada dessa perspectiva francesa - mais ligada aos campos psicossociológico e sociológico - no Brasil está intimamente relacionada à história do Setor de Psicologia Social da Universidade Federal de Minas Gerais (UFMG).

Desde o final dos anos 1960, "o Setor" - alcunha pela qual ficou conhecido - incorporou a AI francesa como um de seus referenciais, tendo recebido, em 1972, a visita de Georges Lapassade.... Visita "intempestiva", por sinal, para os tempos ditatoriais, visto que a AI francesa constitui pensamento/prática tendente ao marxismo libertário e/ou ao anarquismo, e Lapassade fora, além do mais, ativo militante do movimento de maio de 1968, enfatizando, à época da estada no Brasil, temas como o anti-colonialismo, a afirmação da homossexualidade e a denúncia do racismo. (Cunha, Dorna \& Rodrigues, 2006, p. 3).

O "Setor" reunia professoras(es) e estudantes de Psicologia e caracterizava-se por colocar em pauta temas praticamente esquecidos (ou negados) pela Psicologia de então, tais como alfabetização de adultas(os), saúde pública, antipsiquiatria, análise de discurso e de conteúdo, psicossociologia francesa, práticas comunitárias e a relação entre Psicologia e poder. Além disso, 
oferecia treinamento em dinâmica de grupos e comunidades terapêuticas, realizava levantamentos socioeconômicos, intervenções psicossociológicas, pesquisas de opinião e de atitudes, preocupandose sempre "em produzir uma psicologia social comprometida com as necessidades da população, especialmente com as classes populares. E é justamente a partir das intervenções realizadas junto a diferentes movimentos e grupos que a Psicologia Social do Setor vai sendo construída." (Cunha, Dorna \& Rodrigues, 2006, p. 5).

Por meio de um projeto de cooperação com a Embaixada da França no Brasil, o Setor recebia professoras(es) francesas(es) e enviava algumas(uns) de suas(eus) integrantes para estudar na França. Entre as(os) professoras(es) que vieram dar cursos e participar de seminários organizados pelo Setor, podemos citar Max Pagès, André Lévy, Georges Lapassade, Pierre Fédida e Michel Foucault (Cunha, Dorna \& Rodrigues, 2006). O contato frequente com essas(es) pesquisadoras(es) deu à AI mineira uma nuance francesa.

\subsection{A Psicologia Sócio-Histórica}

Assim como a AI, a Psicologia Sócio-Histórica começou a se desenvolver no Brasil no final da década de 1970, impulsionada pelo movimento de contraposição às práticas psicológicas hegemônicas daquele período. No entanto, as histórias, influências teóricas e preocupações centrais dessas duas abordagens psicossociais são bastante diferentes.

A "Psicologia Sócio-Histórica" (ou "escola de São Paulo") começou a ser desenvolvida por um grupo de professoras(es) e estudantes da Pontifícia Universidade Católica de São Paulo (PUC-SP). Insatisfeitas(os) com os rumos que tomavam as pesquisas $\mathrm{e}$ intervenções psicossociais na década de 1970, lideradas(os) por Silvia Lane e fortemente influenciadas(os) pela Psicologia HistóricoCultural de Vigotski, essas(es) pesquisadoras(es) buscavam se contrapor às dicotomias (como indivíduo/sociedade e teoria/prática) sustentadas pelo modelo positivista de ciência e construir uma Psicologia comprometida com a transformação da realidade brasileira. Ou seja, buscavam construir uma Psicologia que considerava o "conhecimento científico como práxis, unidade entre saber e fazer" (Bock, Ferreira, Gonçalves \& Furtado, 2007, p. 48), na qual teoria e prática deveriam ser vividas sempre como militância. Para isso, propunham adotar uma nova concepção de "homem": o "homem" social e histórico, bem como um novo método: o materialismo histórico e dialético (Lane, 1984/2007).

Uma das experiências que contribuíram para essa insatisfação com a Psicologia Social hegemônica e para o desejo de construir uma Psicologia comprometida socialmente foi o trabalho que o grupo de Silvia Lane desenvolveu com sindicatos e comunidades operárias de 
Osasco, na Grande São Paulo. Com a colaboração de Alberto Abib Andery e Odette de Godoy Pinheiro - também docentes da PUC-SP esse projeto tinha como finalidade a prevenção em saúde mental da população trabalhadora de um bairro periférico do referido município e, para isso, propunha o desenvolvimento de ações de caráter educativo-preventivo e ações de atendimento ambulatorial (Andery, 1984). Segundo Bock, Ferreira, Gonçalves e Furtado (2007), alunas(os) da PUC-SP naquele período,

os trabalhos de Osasco permitiram um profundo questionamento tanto da metodologia quanto da teoria da psicologia social. Recuperou-se a experiência já consagrada de Paulo Freire com sua obra "Pedagogia do oprimido", leu-se Alberto Merani, debateu-se a necessidade e preponderância do método qualitativo de pesquisa, falou-se em pesquisa-ação o ou pesquisa participante. Questionou-se profundamente o parâmetro teórico da psicologia social. De uma hora para outra, apenas a discussão crítica da Psicologia Social americana não era mais suficiente. (p. 48 , destaque dos autores)

Foi, também, importante para o desenvolvimento da Psicologia SócioHistórica a aproximação de Lane com psicólogas(os) sociais de outros países latino-americanos, como as venezuelanas Maritza Montero e Maria Auxiliadora Banchs, a peruana Gladys Montecinos, o cubano Fernando Gonzalez Rey e o espanhol, radicado em El Salvador, Ignacio Martín-Baró (Bock, Ferreira, Gonçalves \& Furtado, 2007).

Atualmente, a Psicologia Sócio-Histórica está presente em diversos programas de pós-graduação e cursos de graduação em Psicologia, tais como os oferecidos pela Pontifícia Universidade Católica do Rio Grande do Sul (PUC-RS), pela Universidade Federal do Paraná (UFPR), pela Universidade Federal de Santa Catarina (UFSC), pela Universidade Estadual Paulista Júlio de Mesquita Filho (Unesp) e pela própria PUC-SP. Possui, também, um grupo de trabalho na ANPEPP, intitulado "A Psicologia Sócio-Histórica e o Contexto Brasileiro de Desigualdade Social".

\subsection{A Teoria das Representações Sociais}

O termo "representações sociais" foi utilizado pela primeira vez por Serge Moscovici em Psychanalyse: son image et son public (1961) para se referir aos saberes populares e do senso comum, elaborados e partilhados coletivamente com o objetivo de construir e interpretar o real (Oliveira \& Werba, 2007). Moscovici havia percebido que os meios de comunicação difundiam uma série de conceitos psicanalíticos e que esses eram incorporados à linguagem cotidiana de diferentes grupos sociais de uma forma bem "livre", sem fazer 
referência alguma à fundamentação teórica original. Havia percebido também que, nesse movimento, conceitos complexos eram transformados em conhecimento acessível, útil para dar sentido à realidade e justamente é esse processo de transformação de noções acadêmicas em ideias do senso comum que o autor enfoca nessa obra (Álvaro \& Garrido, 2006).

Segundo Celso Pereira de Sá (2007), a Teoria das Representações Sociais (TRS) chegou ao Brasil em 1978, com a publicação da primeira parte do livro de Moscovici. Pouco tempo depois, estudantes latino-americanas(os) - dentre elas(es), algumas(uns) brasileiras(os) - começam a procurar o laboratório de Moscovici na França para fazer cursos de pós-graduação. Segundo o autor, foi a partir da iniciativa dessas(es) estudantes que a TRS penetrou efetivamente no Brasil: "de fato, no seu segundo ingresso no país, em 1982, a teoria veio corporificada na pessoa de uma pesquisadora francesa, Denise Jodelet, que, atendendo aos convites de suas estudantes latinoamericanas, após passar pela Venezuela, desembarcou em Campina Grande, Paraíba." (p. 598).

Jodelet foi uma figura importante para a familiarização de estudantes e estudiosas(os) brasileiras(os) com TRS. Além de desenvolver parcerias com grupos de pesquisa de várias universidades do país, incentivou a realização de eventos sobre a abordagem, promovendo, com isso, aproximações entre pesquisadoras(es) brasileiras(os) e várias(os) autoras(es) europeus - entre elas(es), o próprio Moscovici. De acordo com Sá (2007), com o passar dos anos, "os pesquisadores brasileiros foram se tornando cada vez mais competentes e autônomos em suas atividades de ensino -inicialmente em nível de pós-graduação, mas hoje também na graduação - e de produção de conhecimento nesse domínio da psicologia social." (p. 598). Desse modo, segundo o autor, embora os vários grupos já consolidados de pesquisa ainda mantenham parcerias com países europeus, há um crescente esforço de associação e cooperação internas, cujos resultados têm se mostrado mais evidentes nas atividades do Grupo de Trabalho sobre Representações Sociais, da Associação Nacional de Pesquisa e Pós-graduação em Psicologia (ANPEPP) e nas Jornadas Internacionais sobre Representações Sociais. Esse esforço de cooperação resultou, também, na criação de centros e redes de pesquisa, tais como o "Centro Internacional de Estudos em Representações Sociais e Subjetividade - Educação" (CIERS-ed), o "Centro Internacional de Pesquisa em Representação e Psicologia Social 'Serge Moscovici"" e a "Rede Internacional de Pesquisa sobre Representações Sociais em Saúde" (RIPRES) (Jodelet, 2011) ${ }^{3}$.

Segundo Jodelet (2011), hoje, podemos até mesmo falar em uma "escola brasileira" da TRS. Afinal, já temos um "um grupo de pesquisadores unido por um mesmo estilo e uma mesma preocupação ou orientação" (p. 22). Para a autora, apesar de 
possuírem divergências teóricas e metodológicas, as(os) pesquisadoras(es) que fazem parte dessa "escola" têm em comum a preocupação de entender os (e intervir nos) problemas sociais de seu país. Em suas palavras:

os trabalhos são desenvolvidos essencialmente em torno de temas ou domínios chamados de "aplicação", mas que em efeito, são domínios onde surgem problemas sociais importantes: educação, saúde, ambiente, política e justiça social, movimentos sociais, memória e história... essa orientação social é característica de uma "escola" radicalmente diferente da perspectiva das escolas europeias. Estas se dedicam a processos e temas definidos de maneira teórica para enriquecer a teoria, afinar as metodologias, no laboratório ou no campo; ou para oferecer novas vias de análise dos fenomenos, conceitos e temas da disciplina "psicologia social", opondo-se as correntes tradicionais. (p. 22).

\subsection{Abordagens construcionistas}

Em texto publicado em 1985, no American Psychology, Kenneth Gergen define a investigação construcionista como aquela que se preocupa com a explicitação dos processos por meio dos quais as pessoas descrevem e explicam o mundo em que vivem. Não é propriamente uma teoria, mas um movimento de questionamento das formulações representacionistas sobre produção de conhecimento, que perpassa diferentes campos do saber, tais como a filosofia, a antropologia, a sociologia, a física e a própria Psicologia Social (Spink \& Spink, 2007).

Para Lupicinio Iñiguez (2008), a principal característica desse movimento é o contínuo questionamento daquilo que é considerado óbvio, natural, correto e evidente. Para assumir essa postura crítica e, ao mesmo tempo, reflexiva, autoras(es) construcionistas costumam se basear em alguns pressupostos: o primeiro deles é o antiessencialismo, ou seja, a adoção de uma postura desnaturalizadora, que considera que tanto as pessoas como o mundo em que elas vivem são produtos de processos sociais específicos. Assim, não existiriam objetos naturais: "os objetos são como são porque nós somos como somos, os fazemos, tanto como ele nos fazem e, portanto, não há objetos independentes de nós, nem nós somos independentes deles" (Ibañez, 2001, p. 578). É neste sentido que autoras(es) construcionistas afirmam que a realidade é construída.

Desse modo, a postura construcionista problematiza o modo como aprendemos a olhar para o mundo e para nós mesmos. Questiona a ideia de que podemos produzir conhecimento a partir da observação 
objetiva e imparcial da realidade - como se a ciência fosse um "espelho" que reflete as coisas tal como elas são. Sustenta que a verdade, o bom e o correto são construções sociais (Iñiguez, 2008). Essa é, portanto, uma postura relativista, mas não no sentido de "um idealismo desenfreado porque, ao assumir que nossos critérios para definir valores e verdades são construções nossas, a nossa responsabilidade de adotar posturas éticas e assumir valores aumenta." (Spink \& Spink, 2007, p. 578).

A postura construcionista nos convida a problematizar a essencialização do mundo social e natural, bem como a entender a historicidade e o caráter situado de nossas maneiras (científicas ou não) de compreender o mundo em que vivemos. Ao fazer isso, a linguagem deixa de ser apenas expressiva e adquire um caráter performativo, passando a ser uma "forma de construção da realidade por gerar as categorias a partir das quais pensamos e damos sentidos aos eventos do nosso cotidiano. Como consequência, o conhecimento passa a ser tomado como uma construção coletiva resultante de práticas sociais culturalmente localizadas." (Spink \& Spink, 2007, p. 578).

A reflexão construcionista adentrou no Brasil por duas vias: uma em interlocução com pesquisadores associados ao Taos Institute, que têm Kenneth Gergen como principal referência, e a outra decorrente de aproximações com a filosofia da linguagem, sobretudo Rorty (1994) e mais conectada a pesquisadores da Universidade Autônoma de Barcelona, que têm Tomas Ibañez por principal referência. A interlocução com o Taos Institute se deu por meio de visitas de pesquisadores à Faculdade de Filosofia Ciências e Letras de Ribeirão Preto, sobretudo Sheila McNamee, e por meio da realização de estágios sanduíche em universidades norte-americanas com linhas de pesquisa inspiradas nas reflexões construcionistas. Nesse âmbito, um marco importante foi a tradução do livro "Terapia como construção social" publicada em inglês em 1992 e traduzida para o português em 1998 (McNamee \& Gergen, 1998).

A influência de pesquisadores da Universidade Autônoma de Barcelona foi pontuada por visitas recíprocas de pesquisadores do Programa de Estudos Pós-graduados em Psicologia Social da Pontifícia Universidade Católica de São Paulo e da UAB, sobretudo em diálogo com Lupicinio Iñiguez. Contudo, as reflexões construcionistas já se faziam presentes no Núcleo de Estudos e Pesquisas em Práticas Discursivas no Cotidiano (NUPRAD), com forte influencia da "virada linguística" na filosofia e das correntes da Psicologia Discursiva (por exemplo, Potter \& Wetherell, 1987). Assim, em 1999, pesquisadores afiliados ao NUPRAD organizaram e publicaram uma primeira apresentação da abordagem de análise de práticas discursivas pautada na abordagem construcionista (Spink, 1999). 
Embora compartilhem de pressupostos tais como a especificidade cultural e histórica das maneiras de conhecer o mundo e a valorização da postura crítica e reflexiva, há algumas diferenças decorrentes dessas influências. A corrente derivada das propostas de Gergen tem foco mais relacional, dando primazia aos relacionamentos humanos na produção e sustentação do conhecimento (Rasera, Guanaes \& Japur, 2004; McNamee, 2011). Em contraste, a corrente associada às reflexões de Tomas Ibañez é mais fortemente influenciada pelos estudos de ciência e tecnologia que levam a aproximações com vertentes da sociologia simétrica, sobretudo a Teoria Ator-Rede (Law \& Hassard, 1999).

\section{Considerações finais}

Neste artigo, buscamos contar uma (breve) história da Psicologia Social no Brasil, destacando algumas das abordagens teóricas, grupos de pesquisa e instituições que fizeram e fazem parte desse vasto (e diverso) campo. Ao fazermos isso, acabamos deixando de fora de nossa história uma série de personagens, acontecimentos, saberes e lugares. Não demos conta do todo, afinal, por mais que quiséssemos conhecer, representar ou documentar essa área do conhecimento de forma completa, nós nunca conseguiríamos fazê-lo (Cordeiro, 2012).

Segundo Law (2003), essa limitação não é causada somente por uma inadequação técnica; mas, sobretudo, pelo fato de que tornar algo presente implica, necessariamente, tornar outras coisas ausentes. E "não poderia ser de outra forma. Presença implica ausência." (p. 7). Para o autor, essa limitação constituiria um problema se acreditássemos em sujeitos que tudo sabem, em olhos que tudo veem, em base de dados que tudo representam. No entanto, essa totalidade não passa de uma pretensão, pois

o conhecível é dependente de, está relacionado e é produzido com o não conhecível. Aquilo que está em outro lugar. Ausente. Assim, o problema não está na tentativa de conhecer. Há muitas razões para se tentar conhecer de uma forma ou de outra. Ao invés disso, está no fracasso (ou na recusa) em entender a lógica, o caráter e a política do projeto de conhecimento. No fracasso em pensar através daquilo que está implicado pelo fato de que o conhecimento é constitutivamente incompleto. (Law, 2003, p.7, tradução nossa).

Sendo assim, para Law (2003), o problema de muitas ciências naturais e sociais não está em não mencionar ou em excluir o "outro" - isso é inerente ao processo de tornar algo presente. Mas está na 
negação dessa exclusão. Está na pretensão de ter um saber global, universal e totalizante. Neste artigo, assumimos a incompletude de nossa narrativa sobre a história da Psicologia Social brasileira. Admitimos que nossa narrativa é fruto de escolhas, que "a história é sempre um fazer" (Massimi, 2000, p. 12). Um fazer que não é neutro e que depende do lugar que ocupamos no presente. Afinal, é a partir dele que formulamos nossas perguntas, definimos nossos campos de interesse, escolhemos nossos objetos e selecionamos os documentos que utilizaremos para estuda-los. É a partir desse lugar que "compomos nossa reconstrução trilhando um certo caminho" (p. 11). Desse modo, neste artigo, apresentamos, de forma breve e limitada, algumas das versões da Psicologia Social, deixando, com isso, brechas para que nossas(os) interlocutoras(es) construam outras histórias e outras narrativas sobre o que foi e o que é essa área do conhecimento em nosso país.

\section{Referências}

Álvaro, J. L., \& Garrido, A. (2006). Psicologia Social: perspectivas psicológicas e sociológicas. São Paulo: McGraw-Hill.

Andery, A. A. (1984). Trabalhos em comunidade: seu significado para a produção de novos conhecimentos científicos. Psicologia: ciência e profissão, 4(1), 30-33.

Armistead, N. (Ed.). (1974). Reconstructing Social Psychology. Oxford, UK: Penguin Books Ltd.

Bernardes, J. (2001). História. In M. N. Strey (Ed.), Psicologia Social Contemporânea: livro-texto (5. ed., pp. 19-35). Petrópolis: Vozes.

Bock, A. M. B., Ferreira, M. R., Gonçalves, M. G. M., \& Furtado, O. (2007). Silvia Lane e o projeto do compromisso social da Psicologia. Psicologia \& Sociedade, 19(ed. esp. 2), 46-56.

Bock, A. M. B., Furtado, O. (2007). A psicologia no Brasil e suas relações com o marxismo. In A. M. Jacó-Vilela, A. A. L. Ferreira \& F. T. Portugal (Orgs.), História da psicologia: rumos e percursos (pp. 503-513). Rio de Janeiro: Nau.

Bomfim, E. M. (2003). Contribuições para a história da Psicologia no Brasil. In A. M. Jacó-Vilela, M. L. Rocha \& D. Mancebo (Orgs.), Psicologia Social: relatos na América Latina (pp. 123-144). São Paulo: Casa do Psicólogo.

Cordeiro, M. P. (2017). A fractalidade da Psicologia Social. In N. Silva Júnior \& W. Zangari (Orgs.), A Psicologia Social e a Questão do hífen (pp. 41-56). São Paulo: Blucher.

Cordeiro, M. P. (2013). Psicologias sociais cientificista e crítica: um debate que continua. Psicologia: ciência e profissão, 33(3), 716-729. 
Cordeiro, M. P. (2012). Psicologia Social no Brasil: multiplicidade, performatividade, controvérsias (Tese de doutorado não publicada). Pontifícia Universidade Católica de São Paulo, Programa de Estudos Pós-Graduados em Psicologia Social, São Paulo, Brasil.

Cordeiro, M. P., \& Spink, M. J. (2014). A multiplicidade da Psicologia Social Brasileira. Athenea Digital, 14(1), 289-300.

Coordenação de Aperfeiçoamento de Pessoal de Nível Superior [Capes]. (2016a). Plataforma Sucupira. Recuperado de https://sucupira.capes.gov.br/sucupira/public/consultas/coleta/ programa/listaPrograma.jsf

Coordenação de Aperfeiçoamento de Pessoal de Nível Superior [Capes]. (2016b). Documento de área - Psicologia. Recuperado de

http://capes.gov.br/images/documentos/Documentos_de_area _2017/PSIC_docarea_15fev2017.pdf

Cunha, A. A. G., Dorna, L. B. H., \& Rodrigues, H. B. C. (2006). Uma contribuição à história da Análise Institucional no Brasil através de depoimentos orais: o Setor de Psicologia Social da Universidade Federal de Minas Gerais (UFMG) nas décadas de 1960 e 1970. Mnemosine, 2(1), 2-11.

Ferreira, M. C. (2011). Breve história da moderna psicologia social. In C. V. Torres, \& E. R. Neiva (Orgs.), Psicologia Social: principais temas e vertentes (pp. 13-30). Porto Alegre: Artmed.

Gergen, K. J. (1985). The social construcionist movement in modern psychology. American Psychologist, 40(3), 266-275.

Ibáñez, T. (2001). Municiones para disidentes. Barcelona: Gedisa.

Iñiguez, L. (2008). La Psicología Social en la encrucijada postconstruccionista: historicidad, subjetividad, performatividad, acción. In N. Guareschi (Org.), Estratégias de invenção do presente: a psicologia social no contemporâneo (pp. 5-42). Rio de Janeiro: Centro Edelstein de Pesquisas Sociais.

Israel, J., \& Tajfel, H. (Eds.) (1972). The context of Social Psychology: A Critical Assessment. Londres, UK: Academic Press.

Jacó-Vilela, A. M. (2007). O estatuto da psicologia social: contribuições da história da psicologia social. In C. Mayorga, \& M. A. M. Prado (Orgs.), Psicologia Social: articulando saberes e fazeres (pp. 37-54). Belo Horizonte: Autêntica.

Jodelet, D. (2011). Ponto de vista: sobre o movimento das representações sociais na comunidade científica. Temas em Psicologia, 19(1), 19-26.

Lallement, M. (2008). História das idéias sociológicas: de Parsons aos contemporâneos ( $3^{\mathrm{a}}$. ed.). Petrópolis: Vozes. 
Lane, S. T. M. (1984/2007). A Psicologia Social e uma nova concepção do homem para a Psicologia. In S. T. M. Lane \& W. Codo (Eds.), Psicologia Social: o homem em movimento (13a. ed., pp. 10-19). São Paulo: Brasiliense.

Lane, S. T. M. (1996). Histórico e fundamentos da psicologia comunitária no Brasil. In R. H. F. Campos (Org.), Psicologia Social Comunitária: da solidariedade à autonomia (pp. 17-34). Petrópolis: Vozes.

Lane, S. T. M., \& Bock, A. M. B. (2003). Abrapso - uma história da Psicologia Social enquanto práxis. In A. M. Jacó, Vilela, M. L. Rocha, \& D. Mancebo (Orgs.), Psicologia Social: relatos na América Latina (pp. 145-155). São Paulo: Casa do Psicólogo.

Law, J. (2003). Making a mess with method. In Centre For Science Studies. Lancaster-UK: University of Lancaster. Recuperado em 15 de fevereiro de 2009, de http://www.lancs.ac.uk/fass/sociology/papers/law-making-amess-with-method.pdf

Law, J. \& Hassard, J. (Orgs.) (1999). Actor Network Theory and After. Oxford, UK.: Blackwell.

Liedke Filho, E. D. (2003). Sociologia Brasileira: tendências institucionais e epistemológico-teóricas contemporâneas. Sociologias, 1(9), 216-245.

Mancebo, D., Jacó-Vilela, A. M., \& Rocha, M. L. (2003). Psicologia Social e História: um encontro necessário. In A. M. Jacó-Vilela, M. L. Rocha, \& D. Mancebo (Orgs.), Psicologia Social: relatos na América Latina (pp. 7-18). São Paulo: Casa do Psicólogo.

Massimi, M. (2000). Historiar a Psicologia: assumindo uma perspectiva e um lugar de observação. In A. M. Jacó-Vilela, $H$. C. Rodrigues, M. H. S. Patto, \& M. Massimi (Orgs.), Anais do I Seminário de Historiografia da Psicologia (pp. 11-32). São Paulo: GEHPAI/Fapesp.

Mcnamee, S. (2011). From social construction to relational construction: practices from the edge. Psychological Studies, 57(2), 150-156.

McNamee, S., \& Gergen, K. (Orgs.). (1998). A terapia como construção social. Porto Alegre: Artes Médicas.

Moscovici, S. (1961). La Psychanalyse: son image et son public. Paris: PUF.

Oliveira, F. O., \& Werba, G. C. (2007). Representações Sociais. In M. N. Strey (Ed.), Psicologia Social contemporânea: livro-texto (10 ${ }^{\mathrm{a}}$. ed., pp. 104-117). Petrópolis: Vozes.

Potter, J., \& Wetherell, M. (1987). Discourse and social psychology: beyond attitudes and behaviour. London: Sage Publications.

Rasera, E. F., Guanaes, C., \& Japur, M. (2004). Psicologia, ciência e construcionismos: dando sentido ao self. Psicologia: Reflexão e Crítica, 17(2), 157-165. 
Rodrigues, A (1972/2012). Psicologia social (30ª . ed.). Petrópolis, RJ: Vozes.

Rorty, R. (1994). A filosofia e o espelho da natureza. Rio de Janeiro: Relume-Dumará.

Sá, C. P. (2007). As representações sociais na história recente e na atualidade da Psicologia Social. In A. M. Jacó-Vilela, A. A. L. Ferreira, \& F. T. Portugal (Orgs.), História da Psicologia: rumos e percursos (pp. 587-602). Rio de Janeiro: Nau.

Spink, M. J. (Org.) (1999). Práticas discursivas e produção de sentidos no cotidiano: aproximações teóricas e metodológicas. São Paulo: Cortez.

Spink, M. J., \& Spink, P. K. (2007). A psicologia social na atualidade. In A. M. Jacó-Vilela, A. A. L. Ferreira, \& F. T. Portugal (Orgs.), História da Psicologia: rumos e percursos (pp. 565-585). Rio de Janeiro: Nau.

Tittoni, J., \& Jacques, M. G. C. (2001). Pesquisa. In M. N. Srey (Org.). Psicologia Social Contemporânea: livro texto ( $5^{a}$. ed., pp. 73-85). Petrópolis: Vozes.

\section{Endereço para correspondência \\ Mariana Prioli Cordeiro}

Universidade de São Paulo

Instituto de Psicologia - IPUSP

Avenida Professor Mello de Morais, 1721, Cidade Universitária, CEP 05508-030, São

Paulo - SP, Brasil

Endereço eletrônico: mpriolicordeiro@usp.br

\section{Mary Jane Paris Spink}

Pontifícia Universidade Católica de São Paulo - PUC-SP

Programa de Estudos Pós-graduados em Psicologia Social

Rua Monte Alegre, 984, Perdizes, CEP 05014-901, São Paulo - SP, Brasil

Endereço eletrônico: mjspink@pucsp.br

Recebido em: $14 / 10 / 2018$

Aceito em: $11 / 01 / 2019$

\section{Notas}

* Doutorado em Psicologia Social pela Pontifícia Universidade Católica de São Paulo.

** Doutorado em Psicologia Social pela Universidade de Londres.

1 É importante destacar que a chamada "crise de referência" não substituiu completamente a Psicologia Social "norte-americana" pela "crítica". Afinal, ainda temos programas de pós-graduação que desenvolvem pesquisas experimentais, os livros clássicos dessa abordagem continuam sendo reeditados - o manual "Psicologia Social", de Aroldo Rodrigues (1972/2012), por exemplo, está na 30a edição - e cobrados como leitura básica de disciplinas acadêmicas e concursos públicos. A "crise" foi um movimento de questionamento, que estimulou o desenvolvimento de uma série de abordagens psicossociais, fazendo com que a Psicologia Social "norte-americana" deixasse de ser hegemônica, mas não a eliminando completamente (Cordeiro, 2013). 
2 Para identificar tais programas, consultamos a Plataforma Sucupira (https://sucupira.capes.gov.br/). Nela, realizamos uma busca por programas utilizando três filtros: 1) área básica: psicologia social; Programa: Psicologia Social e 2) situação do programa: em funcionamento (sendo que os dois primeiros foram combinados com o terceiro). Já as linhas de pesquisa foram informadas pelos sites dos programas listados na Plataforma.

${ }^{3}$ O CIERS-ed está situado em São Paulo e reúne pesquisadoras(de) de cerca de trinta universidades brasileiras (http://www.fcc.org.br/pesquisa/ciers.html). Já o Centro Serge Moscovici fica em Brasília e promove o intercambio entre pesquisadoras(es) da Universidade de Brasília (UnB), Universidade Federal do Espírito Santo (UFES), Universidade Federal de Pernambuco (UFPE), Universidade Católica de Brasília (UCB), Universidade do Estado do Rio de Janeiro (UERJ) e Universidade Federal do Rio de Janeiro (UFRJ) (http://www.centromoscovici.unb.br). A RIPRES, por sua vez, articula centros de pesquisa brasileiros, argentinos, austríacos, escoceses, franceses, italianos, mexicanos e portugueses (http://www.cicts.uevora.pt/RIPRES).

A pesquisa contou com auxílio do Conselho Nacional de Desenvolvimento Científico e Tecnológico (CNPq), bem como da Fundação de Amparo à Pesquisa do Estado de São Paulo (Fapesp).

Este artigo de revista Estudos e Pesquisas em Psicologia é licenciado sob uma Licença Creative Commons Atribuição-Não Comercial 3.0 Não Adaptada. 